\title{
Relationship between dental caries, oral hygiene and malocclusion among Syrian refugee children and adolescents: a cross-sectional study
}

\author{
Nesreen A. Salim ${ }^{*}$, Rasha A. Alamoush ${ }^{1}$, Mariam Mohammad Al-Abdallah², Aya Ahmed Al-Asmar ${ }^{3}$ and \\ Julian D. Satterthwaite ${ }^{4}$
}

\begin{abstract}
Background: Little is known about the oral disease burden in refugee children and associated risk factors. This crosssectional study aimed to explore the oral hygiene status and prevalence of caries, and to investigate their association with malocclusion characteristics in a child refugee population.

Methods: 606 Syrian refugee children and adolescents aged 7-19 years, registered as refugees in Jordan and residing in Zaatari camp, were recruited to the study. Oral hygiene and caries status were recorded using DMFT (mean of decayed, missing, and filled permanent teeth) and OHI-S (Simplified Oral Hygiene Index) according to WHO criteria. Oral health results were then cross tabulated with previously reported malocclusion traits for the same study sample (crowding, spacing, contact point deflection and IOTN) to detect any associations. Statistical analysis was conducted using chi-square test, independent sample t-test, one-way ANOVA, Welch test and Post Hoc testing (Gabriel and Games-Howell).

Results: Overall DMFT and OHI-S were 4.32 and 1.33 respectively with no difference between males and females. Around $40 \%$ of the sample showed $\geq 5$ DMFT score. $96.1 \%$ of the sample either do not brush or brush occasionally: females showed better oral hygiene practices $(P=0.002)$. No significant differences in DMFT scores were noted for gender or age, other than the 7-9.9 year old group having significantly higher mean DMFT scores than all other age groups $(P<0.01)$; the mean of OHI-S was not significantly different between different age groups $(P=0.927)$. Subjects with malocclusion, specifically crowding, contact point deflection and IOTN grades 3, 4 and 5 had higher scores in both arches for OHI-S and DMFT than subjects without malocclusion traits, although this was not statistically significant for DMFT scores. Overall, patients with generalized spacing had a significantly lower OHI-S score than those without spacing $(P=0.021)$. Significant correlations were found between parameters of intra-arch and inter-arch relationships and oral health indices (DMFT and OHI-S).
\end{abstract}

Conclusion: Malocclusion may increase the risk of caries and periodontal disease; the magnitude of this risk is amplified in populations with poor oral health and limited access to oral healthcare services, highlighting the need for preventive and curative oral health programs.

\footnotetext{
*Correspondence: n.salim@ju.edu.jo

1 Prosthodontic Department, School of Dentistry, The University

of Jordan, Amman 11942, Jordan

Full list of author information is available at the end of the article
} original author(s) and the source, provide a link to the Creative Commons licence, and indicate if changes were made. The images or other third party material in this article are included in the article's Creative Commons licence, unless indicated otherwise in a credit line to the material. If material is not included in the article's Creative Commons licence and your intended use is not permitted by statutory regulation or exceeds the permitted use, you will need to obtain permission directly from the copyright holder. To view a copy of this licence, visit http://creativecommons.org/licenses/by/4.0/. The Creative Commons Public Domain Dedication waiver (http://creativecommons.org/publicdomain/zero/1.0/) applies to the data made available in this article, unless otherwise stated in a credit line to the data. 
Keywords: Dental caries, Malocclusion, Refugee, Oral health, Oral hygiene index, DMF index

\section{Background}

Malocclusion has been associated with psychosocial distress, discomfort, low quality of life, poor periodontal condition, and impaired masticatory function $[1,2]$. This impacts quality of life and leads to increased demand for orthodontic treatment, especially for children and adolescents with this age group being susceptible to psychological trauma and influence on educational and social skills $[3,4]$. The dental health component $(\mathrm{DHC})$ of the Index of Orthodontic treatment Needs (IOTN) [5] aims to quantify treatment need based on the harmful effects of malocclusion: heterogeneous values of orthodontic treatment needs have been reported in different countries ranging from $71 \%$ in Jordanian school children to $93 \%$ in 11-14-year-old Italian children [6, 7]. Differences in ethnicity and study methodology underlie some of these variations [5].

Dental caries, along with periodontal disease, contributes significantly to the global burden of chronic diseases $[8,9]$, although the influence of malocclusion on disease levels is unclear, with conflicting results in relation to both periodontal condition [10, 11], and also caries [12-15]. Some traits of malocclusion might hamper efficient oral hygiene [16, 17]: for example, crowding is highly correlated to increased plaque indices and gingival inflammation [18] and caries may be associated with spacing [12], crowding [19], and increased or reduced overbite $[12,13]$. Also, caries and early tooth loss may in turn lead to occlusal irregularities and malocclusion [20]. However, maintenance of good oral hygiene may be more important than the improvement provided by orthodontic treatment $[10,11]$.

Children and adolescents constitute about $35.2 \%$ of the total refugee population in Jordan [21] (nearly 330,000 below 17 years) and about $56.0 \%$ of the Zaatari camp population (over 43,000 below 17 years). Rates of dental disease have increased since the war in Syria began, and caries is the second most commonly reported health issue among refugees after the common cold [22], with the high prevalence of dental disease among immigrants and refugees being attributed to the difficulties in accessing dental services, cost, poor quality nutrition, poor diet and low priority given to dental care during the migration process [23-25].

The presence of malocclusion in refugee populations may further complicate their already-deteriorated oral health and negatively affect quality of life [26, 27]; however, the relationship between dental caries, oral hygiene and malocclusion has not yet been investigated in Syrian refugee children and adolescents and such information is important to target healthcare services and priorities according to an evidence-base. The aim of this study was to evaluate the overall oral health of refugee children to investigate any association with malocclusion traits. The specific objectives were to assess oral health using DMFT index and oral hygiene scores (OHI-S) and to evaluate any relationship to existing orthodontic problems.

\section{Methods}

\section{Study design and study group}

A cross-sectional clinical survey was conducted from October 2019 to December 2019. Participants were Syrian refugee children and adolescents aged 7-19 years, registered as refugees in Jordan and residing in Zaatari camp. All child attendees/parents to the camp dental clinic during this period were invited to participate.

\section{Demographic and general dental data}

Gender, age, and oral habits were recorded. Age was categorized into: A1: 7-9.9 yrs., A2: 10-12.9 yrs., A3: 13-15.9 yrs., A4: 16-19 yrs.

\section{Clinical examination}

Examination was carried out by a prosthodontist (first author) who had been previously trained in the standardized diagnostic criteria and the basic methods outlined by the WHO [28], assisted by 2 junior dentists. Prior to the main study, a group of 30 patients aged 7-19 years (not part of the study sample) were examined for intraexaminer calibration, with an excellent level of agreement (Cohen's kappa coefficient $=0.94$ ). A total of 606 individuals were examined in Zaatari dental clinics. The clinics had a high level of attendance, and there was thus no need for further active recruitment.

Sample size was calculated prior to data collection using expected sample size formula. Our target population were children and adolescents in Zaatari camp (around 37,000) and with a power of $85 \%$, alpha value of 0.05 (a margin of error of 5\%), and a confidence interval of $95 \%$ the calculated sample was 381 [29]. Therefore we aimed for a sample of around 600 to take into consideration that our study included multiple comparisons of proportions and ranked values.

Dental examinations were carried out on reclined patients using a basic disposable oral mirror and a WHO periodontal probe. The average time for examination time of each child was approximately $5 \mathrm{~min}$. An oral health assessment form was developed, based on 
the model suggested by the WHO [28]; for each patient demographic (age, gender); frequency of tooth brushing was recorded, as well as clinical variables as below:

\section{Dental caries}

1. Inspection of caries prevalence and history was measured using DMFT (mean of decayed, missing, and filled permanent teeth).

2. Significant caries index $(\mathrm{SiC})$ was obtained by calculating the mean DMFT/dmft score of the third of the population with the highest DMFT/dmft [30]. With $\mathrm{SiC} / \mathrm{dmft}$ being the significant caries index for primary teeth and $\mathrm{SiC} / \mathrm{DMFT}$ being the significance caries index for permanent teeth.

\section{Oral hygiene}

Oral hygiene status was registered using the oral hygiene index simplified (OHI-S) (a combination of the debris index and the dental calculus index to determine the status of oral hygiene). For those participants aged 5 to 6 years, labial surfaces of the 54, 64, 61, 82 and the lingual surface of 75 and 85 were assessed. For mixed dentitions the labial surface of 26 and the lingual surface of 46 were also considered. For participants with most of their permanent teeth the labial surfaces of 11, 26, 16, 31 and the lingual surfaces of 36 and 46 were examined [31].

\section{Statistical analysis}

Data were assessed using SPSS version 23.0 (IBM Corp. Armonk, NY). Descriptive analysis and frequency tables were used for general description; a chi-square test was performed to identify any significant differences in the mean of the DMFT and OHI-S between gender and age groups. The mean of the DMFT and OHI-S was compared between genders using an independent sample t-test. To compare the DMFT and OHI between the four age groups as well as the five oral hygiene method groups, the homogeneity of variances was tested. For those proved homogeneous, one-way ANOVA was used, otherwise a Welch test was used. Significant differences between any of the tested groups were further investigated by Post Hoc testing (Gabriel and Games-Howell) to identify groups that were significantly different. The level of significance was set at $P<0.05$.

The results of oral health were cross tabulated with malocclusion findings that have been reported previously for the same population sample (crowding, spacing IOTN and contact point deflection) [32].

\section{Results}

\section{Descriptive statistics of the sample}

606 children/adolescents participated in the study. 96.2\% of the sample was fit and healthy and the remaining suffered from chronic disorders such as asthma, epilepsy and allergy. Demographics and oral hygiene practices are given in Table 1. The proportion with poor oral hygiene practices (did not brush) was significantly worse in males $(P=0.008)$, and those reporting good oral hygiene practices (brush once) was significantly higher in females $(P=0.002$, Table 1$)$.

The mean DMFT was 4.32 (4.33 for males and 4.31 for females); $92.4 \%$ of the subjects had a DMFT score $>0$ and $39.4 \%$ of subjects had a DMFT $\geq 5.0$ with a significant caries index $(\mathrm{SiC})$ of 8 (Fig. 1). The mean of oral hygiene index simplified (OHI-S) was 1.33 (1.32 for males and 1.35 for females). No significant differences in DMFT were noted for gender or age, other than the 7-9.9 year old group having significantly higher mean DMFT than other age groups $(P<0.01)$.

Children with IOTN grade 3,4 and 5 had significantly higher OHI-S than grade $1(P<0.01)$. The OHI-S in subjects with IOTN grade 1 was significantly lower than subjects with grade 3 and $4(P=0.031, P<0.001$ respectively: Table 2). Regression analysis showed that DMFT was not significantly correlated to the IOTN $(P=0.248)$, while $\mathrm{OHI}$ was significantly and positively correlated to the $\operatorname{IOTN}(P=0.002)$.

OHI-S was significantly lower in those with no arch crowding compared to those with moderate and severe crowding $(P=0.001)$, and those with mild crowding had

Table 1 Age groups and oral health methods by gender

\begin{tabular}{|c|c|c|c|c|}
\hline \multirow[t]{2}{*}{ Parameters } & \multicolumn{2}{|c|}{ Gender N (\%) } & \multicolumn{2}{|c|}{$\begin{array}{l}\text { Total } \\
(\mathrm{N}=606)\end{array}$} \\
\hline & $\begin{array}{l}\text { Male } \\
280(46.2)\end{array}$ & $\begin{array}{l}\text { Female } \\
326(53.8)\end{array}$ & $\mathbf{N}$ & $\%$ \\
\hline \multicolumn{5}{|l|}{$\begin{array}{l}\text { Age } \\
\text { (years) }\end{array}$} \\
\hline A1 (7-9.9) & $47(17)$ & $27(8)$ & 74 & 12.2 \\
\hline A2 (10-12.9) & $141(50)$ & $181(56)$ & 322 & 53.1 \\
\hline A3 (13-15.9) & $79(28)$ & $96(29)$ & 175 & 28.9 \\
\hline A4 (16-19) & $13(5)$ & $22(7)$ & 35 & 5.8 \\
\hline \multicolumn{5}{|l|}{ Oral hygiene method } \\
\hline None* & $97(35)$ & $69(21)$ & 166 & 27.4 \\
\hline Rinse only & $4(1)$ & $1(0.3)$ & 5 & 0.8 \\
\hline Irregular brush & $118(42)$ & $130(40)$ & 248 & 40.9 \\
\hline Brush once a day* & $22(8)$ & $64(19.7)$ & 86 & 14.2 \\
\hline Brush twice a day & $39(14)$ & $62(19)$ & 101 & 16.7 \\
\hline
\end{tabular}

$\mathrm{N}$ : Number of subjects

* Significance difference between males and females at $P<0.01$ 


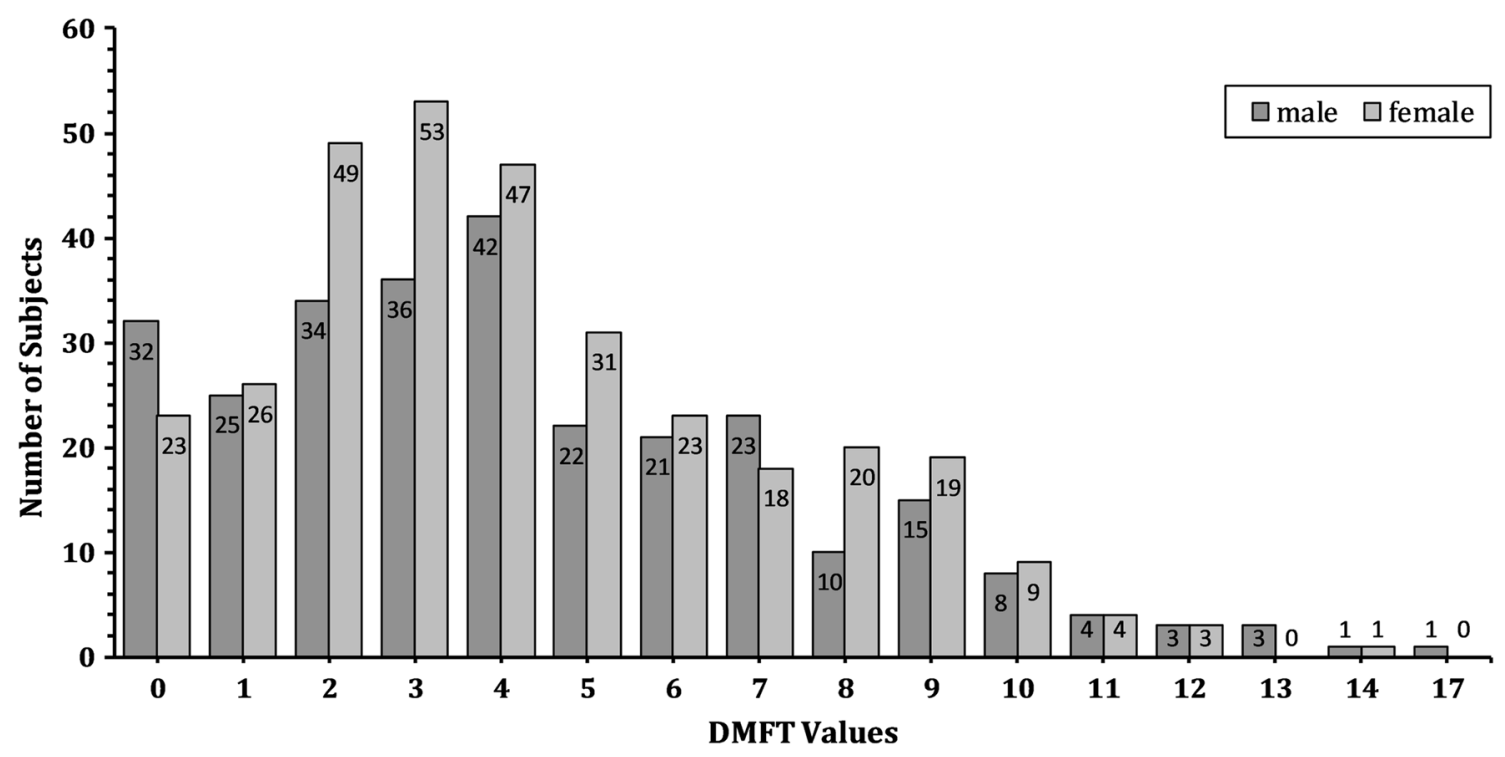

Fig. 1 The range from 0 to 17 for DMFT count data of the study sample according to gender

Table 2 Comparison of DMFT and OHI-S means by IOTN group

\begin{tabular}{|c|c|c|c|c|c|c|}
\hline \multirow{2}{*}{\multicolumn{2}{|c|}{$\begin{array}{l}\text { Index on orthodontic treatment need } \\
\text { (DHC) }\end{array}$}} & \multicolumn{2}{|l|}{ I-Gender N (\%) } & \multirow{2}{*}{$\begin{array}{l}\text { Total }(\mathrm{N}=606) \\
\mathrm{N}(\%)\end{array}$} & \multicolumn{2}{|c|}{ II-Overall OH indices } \\
\hline & & Males $(\mathrm{N}=\mathbf{2 8 0})$ & $\begin{array}{l}\text { Females } \\
(\mathrm{N}=326)\end{array}$ & & $\begin{array}{l}\text { DMFT } \\
\text { Mean (SD) }\end{array}$ & $\begin{array}{l}\text { OHI-S } \\
\text { Mean (SD) }\end{array}$ \\
\hline \multicolumn{7}{|c|}{ Grades and treatment needs } \\
\hline Grade 1 & No need & $53(19)$ & $49(15)$ & $102(16.8)$ & $3.85(2.55)$ & $1.09^{*} a \neq(0.57)$ \\
\hline Grade 2 & Little need & $41(15)$ & $53(16)$ & $94(15.5)$ & $4.55(3.08)$ & $1.34(0.72)$ \\
\hline Grade 3 & Borderline need & $81(29)$ & $82(25)$ & $163(26.9)$ & $4.05(2.90)$ & $1.33^{*}(0.76)$ \\
\hline Grade 4 & Definitive need & $88(31)$ & $123(38)$ & $211(34.8)$ & $4.63(3.29)$ & $1.44^{\alpha}(0.90)$ \\
\hline Grade 5 & & $17(6)$ & $19(6)$ & $36(5.9)$ & 4.39 (3.39) & $1.47^{*}(0.80)$ \\
\hline
\end{tabular}

*a*Significant difference at $P^{<} 0.05$ in the same column

significantly lower OHI-S than those with severe crowding $(P=0.005)$. OHI-S was significantly and positively correlated to the severity of crowding in both arches $(P<0.001)$, and significantly and negatively correlated to the severity of spacing in the upper arch $(P=0.002)$ and in the lower arch $(P=0.031)$. OHI-S was not significantly different based on the severity of lower arch spacing although those with no upper arch spacing had significantly higher mean OHI-S than those with generalized spacing $(P=0.001)$. The DMFT was not significantly different based on the severity of upper or lower arch crowding $(P=0.153$ and 0.158 , respectively: Table four), although was significantly higher for those with generalized lower arch spacing than with no spacing. $(P=0.014)$. Overall, patients with generalized spacing had significantly lower OHI-S than patients with no spacing $(P=0.021)$ and patients with generalized spacing had significantly higher DMFT than patients with no spacing $(P=0.014$, Table 3$)$.

In the upper arch, patients with no contact point deflection had significantly lower OHI-S than those with deflection of $1-2 \mathrm{~mm}$ and > $4 \mathrm{~mm}(P=0.007$ and $P=0.004$, respectively); those with deflection $1 \mathrm{~mm}$ had significantly lower OHI-S than other groups $(P<0.001, P=0.002, P<0.001$ respectively). However in the lower arch, patients with no lower contact point deflection had significantly lower OHI-S compared to those with deflection of ' $4 \mathrm{~mm}(P=0.004)$; those with lower arch contact point deflection of ${ }^{<} 1 \mathrm{~mm}$ had significantly lower OHI-S than those with deflection of $2-4 \mathrm{~mm}$ and $>4 \mathrm{~mm}(P=0.013$ and $P<0.001$, respectively). Patients with lower arch contact point deflection of 1-2 $\mathrm{mm}$ had significantly lower OHI than those with deflection of $>4 \mathrm{~mm}(P=0.036$, Table 4$)$. OHI-S was significantly and positively correlated to 
Table 3 Comparison of DMFT and OHI-S means by crowding and spacing

\begin{tabular}{|c|c|c|c|c|c|c|c|}
\hline \multirow[t]{2}{*}{ Parameters } & \multicolumn{4}{|l|}{ Crowding } & \multicolumn{3}{|l|}{ Spacing } \\
\hline & None & Mild & Moderate & Severe & None & Localized & Generalized \\
\hline \multicolumn{8}{|l|}{ Upper } \\
\hline \multicolumn{8}{|l|}{ Mean (SD) } \\
\hline DMFT & $4.21(3.05)$ & $4.03(2.75)$ & $4.55(3.25)$ & $4.86(3.27)$ & $4.36(3.00)$ & $3.87(2.76)$ & $4.59(3.61)$ \\
\hline $\mathrm{OHI}-\mathrm{S}$ & $1.18^{* a *}(0.64)$ & $1.37^{*}(0.78)$ & $1.57^{a}(0.90)$ & $1.48^{*}(0.96)$ & $1.39 *(0.84)$ & $1.28(0.59)$ & $1.09^{*}(0.64)$ \\
\hline \multicolumn{8}{|l|}{ Lower } \\
\hline \multicolumn{8}{|l|}{ Mean (SD) } \\
\hline DMFT & $4.32(3.11)$ & $4.19(2.95)$ & $4.00(2.92)$ & $5.01(3.25)$ & $4.24^{*}(2.98)$ & $4.02(2.91)$ & $5.37^{*}(3.69)$ \\
\hline $\mathrm{OHI}-\mathrm{S}$ & $1.21^{* *}(0.70)$ & $1.27^{a}(0.64)$ & $1.48^{*}(0.97)$ & $1.71^{¥ a}(1.03)$ & $1.36(0.81)$ & $1.32(0.66)$ & $1.09(0.62)$ \\
\hline
\end{tabular}

* a* Significance differences at $P<0.05$ in the same row for each parameter

Table 4 Comparison of DMFT and OHI-S means by contact deflection

\begin{tabular}{|c|c|c|}
\hline \multirow[t]{2}{*}{ Deflection } & $\begin{array}{l}\text { DMFT } \\
\text { Mean (SD) }\end{array}$ & $\begin{array}{l}\text { OHI } \\
\text { Mean (SD) }\end{array}$ \\
\hline & $P=0.576$ & $P=0.000$ \\
\hline \multicolumn{3}{|l|}{$\begin{array}{l}\text { Upper arch } \\
\text { (n) }\end{array}$} \\
\hline $\begin{array}{l}\text { None } \\
\text { (149) }\end{array}$ & $4.11(2.67)$ & $1.19(0.63)^{* a}$ \\
\hline $\begin{array}{l}<1 \mathrm{~mm} \\
(84)\end{array}$ & $4.45(3.35)$ & $1.00(0.53)^{¥ \Omega 4}$ \\
\hline $\begin{array}{l}1-2 \mathrm{~mm} \\
(129)\end{array}$ & $4.10(2.89)$ & $1.48(0.79)^{* *}$ \\
\hline $\begin{array}{l}2-4 \mathrm{~mm} \\
(118)\end{array}$ & $4.32(2.84)$ & $1.35(0.76)^{\Omega}$ \\
\hline $\begin{array}{l}>4 \mathrm{~mm} \\
(126)\end{array}$ & $4.68(3.58)$ & $1.56(1.00)^{\mathrm{a} \psi}$ \\
\hline \multirow[t]{2}{*}{ Deflection } & $\begin{array}{l}\text { DMFT } \\
\text { Mean (SD) }\end{array}$ & $\begin{array}{l}\text { OHI } \\
\text { Mean (SD) }\end{array}$ \\
\hline & $P=0.364$ & $P=0.000$ \\
\hline
\end{tabular}

Lower arch

(N)

\begin{tabular}{|c|c|c|}
\hline $\begin{array}{l}\text { None } \\
\text { (127) }\end{array}$ & $4.09(2.84)$ & $1.21(0.73)^{*}$ \\
\hline $\begin{array}{l}<1 \mathrm{~mm} \\
(150)\end{array}$ & $4.22(2.99)$ & $1.16(0.62)^{a \Omega}$ \\
\hline $\begin{array}{l}1-2 \mathrm{~mm} \\
(135)\end{array}$ & $4.10(2.80)$ & $1.31(0.68)^{¥}$ \\
\hline $\begin{array}{l}2-4 \mathrm{~mm} \\
(100)\end{array}$ & $4.67(3.42)$ & $1.48(0.86)^{a}$ \\
\hline $\begin{array}{l}>4 \mathrm{~mm} \\
(94)\end{array}$ & $4.70(3.32)$ & $1.66(1.02)^{* \Omega *}$ \\
\hline
\end{tabular}

the severity of contact point deflection in both arches $(P<0.001)$. Patients who brushed twice a day had significantly lower OHI-S scores compared to patients who reported no brushing $(P<0.001)$ and patients with irregular brushing habits $(P<0.001)$. DMFT scores showed no differences between all groups $(P=0.652$, Table 5).

\section{Discussion}

The data concerning the extent of the oral health burden experienced by a growing number of refugees worldwide is limited [33]. Generally, oral health information about this underprivileged population suggests poor oral health and weak oral hygiene practices [22, 23]. To our knowledge, this is the first study to investigate the association between oral health status and malocclusion characteristics in child/adolescent refugees.

This study clearly demonstrated that the oral health status of child refugees in Zaatari camp (the second largest refugee camp worldwide) compares poorly with that of the general population and other child refugee populations, with very high unmet oral health needs [34-36]. Surprisingly, the oral health status of the refugee children in this study showed inferior oral health status compared to other Syrian refugees residing in districts outside the camp in the same country (Jordan); this could be because better overall services are provided outside the camp [37]. The prevalence of caries was $92.4 \%$, which is a worryingly high percentage, justifying the need for efficient oral health programs to ensure that dental needs are targeted efficiently, appropriately and in a timely manner. Moreover, nearly $96 \%$ of this population showed none or very poor oral hygiene practices, which is a major factor to maintain adequate oral health, as highlighted by those with good oral hygiene practices showing significantly lower OHI-S scores.

Limited financial resources, scarcity of healthcare services, limited accessibility to proper nutrition and clean water, and being in a new community outside the habitual healthcare system, all are risk factors that increase oral health diseases and negatively affect the quality of life $[22,23,38]$. In addition, dental care is not frequently considered a main concern among refugees except for pain-associated emergencies as difficulty 
Table 5 Comparison of DMFT and OHI-S means by oral hygiene ( 1 = none, 2 = rinse only, 3 =irregular brushing, $4=$ brush once a day, $5=$ brush twice a day)

\begin{tabular}{lll}
\hline $\begin{array}{l}\text { Oral hygiene method } \\
\text { groups }\end{array}$ & $\begin{array}{l}\text { DMFT } \\
\text { Mean (SD) } \\
\boldsymbol{P}=\mathbf{0 . 6 5 2}\end{array}$ & $\begin{array}{l}\text { OHI-S } \\
\text { Mean (SD) } \\
\boldsymbol{P}=\mathbf{0 . 0 0}\end{array}$ \\
\hline 1 & $4.48(3.2)$ & $1.48(0.89)^{*}$ \\
$\mathrm{~N}=166$ & $3.20(4.1)$ & $1.73(0.77)$ \\
2 & & \\
$\mathrm{~N}=5$ & $4.35(3.0)$ & $1.39(0.78)^{\alpha}$ \\
3 & & \\
$\mathrm{~N}=248$ & $3.94(2.5)$ & $1.22(0.70)$ \\
4 & $4.34(3.1)$ & $1.02(0.60)^{* a}$ \\
$\mathrm{~N}=86$ & \\
5 & \\
$\mathrm{~N}=101$ & \\
${ }^{*} \alpha 1$ and 3 had significantly higher $\mathrm{OHI}-\mathrm{S}$ than 5 at $P<0.01$ &
\end{tabular}

to access dental services is a considerable barrier [36]; subsequently, extraction is the most common treatment provided to child refugees, partly because teeth are severely destructed, and unexpectedly partly due to parental request-even for teeth that can be maintained [36]. This may reflect the lack of education and poor attitude towards the importance of dental treatment and the maintenance of optimal oral health [23]. Moreover, in this camp specifically, the dental services are funded by NGOs and depend on volunteer dentists, and are limited to emergency and routine dental treatment, including restorative care and extractions [23]. All expensive and sophisticated restorative, surgical, and prosthetic dental services are unavailable [23]. Long waiting times and a limited number of dental clinics are other challenging factors [39].

Although there was no significant difference in DMFT and OHI-S scores according to gender, females showed significantly better oral health practices than males concerning brushing frequency. These findings are consistent with previous studies $[40,41]$. However, the negative impact of poor oral hygiene practices, especially in these males, may not manifest itself until adult life [12].

Caries prevalence was related to age, with 7-10 yearolds having the highest DMFT score. This could be related to the dental status at this age where most of primary teeth are carious or lost and many of permanent teeth have not yet erupted. Moreover, at this age the effect of malocclusion is very pronounced, in a growing arch with many erupting teeth and limited manual brushing efficiency compared to other older subjects: all these factors may affect the oral health of those subjects negatively [15].
Oral health status was significantly related to the orthodontic treatment need, especially for subjects with grade 4 or 5 . The occlusal irregularities impede oral hygiene as well as self-cleansing mechanisms, thus result in increased accumulation of dental plaque and/or calculus $[18,41]$. However, although the DMFT scores were higher in grades 3,4 and 5 , these differences were not significant. These results are in line with a previous study [12]. Although DMFT scores did not rise to a significant level, it indicates a trend toward more favorable dental health in subjects with low IOTN levels.

Crowding is an important occlusal trait that has been investigated extensively $[2,18,41]$. In the current study, a significant relation was detected between crowding in both arches and oral hygiene. Even moderate crowding showed higher OHI-S compared to mild or no crowding cases. Differences in methodologies and indices used to evaluate both occlusal and oral hygiene complicate comparisons with previous studies. A weak but significant relationship between occlusal crowding and increased gingivitis has been shown previously [2], additionally a strong association between crowding and gingival inflammation has been shown, however irregularities were not associated with significant gingival inflammation in objects with meticulous oral hygiene practices [18]. Conversely, another study showed no association between crowding and gingival condition [42]. In this study the mean of DMFT was not significantly different based on the severity of crowding in both arches, but all scores increased as the severity of crowding increased, which may indicate a negative impact of crowding on dental health and caries that may manifest in adult life [12]. Previous studies have indicated a significant correlation between crowding and caries $[15,43]$, while others have not shown this correlation [12].

Spacing has been studied as a favorable condition that improves cleansability and thus gingival heath. In this study, spacing in the upper arch was a favorable trait with lower OHI-S compared to subjects with no spacing. This is in line with a previous study, where subjects with spacing in the upper arch showed less gingivitis [41]. However, this was not the case for the lower arch, where the mean OHI-S was not significantly different based on the severity of lower arch spacing, although the scores were lower for subjects with spacing. This may be explained by poorer oral hygiene practices and food accumulation in the lower jaw, and the circumstantially disadvantageous location of lower molars which makes it more difficult to remove plaque from these teeth [44]. Accessibility and manual dexterity of brushing are other factors that may obscure the association between spacing and plaque accumulation in lower arch [41], for example higher DMFT scores in subjects with spacing in the lower arch 
compared to others could be due to food trapping and plaque accumulation and consequently more carious lesions. However, subjects with spacing had lower OHI-S scores than other subjects generally.

Oral health was highly related to the severity of the contact point deflection in both arches. Deflected contacts facilitate food impaction and hinder the effectiveness of oral hygiene practices with those having severe deflections having gingivitis and shallow periodontal pockets $[18,45]$. This is also highlighted by improvement in gingival health with treatment of deflected incisors [46]. However, not all studies have shown a relationship between deflected contacts and number of plaque sites (in the presence of good oral hygiene) [42]. In this study, DMFT values were higher as the severity of deflection increased, and although this difference was not significant it highlights the negative impact of such irregularities on dental health and indicates an increased susceptibility to caries in the future, as has been confirmed by previous studies $[15,43]$.

\section{Limitations}

The main limitation of the present study was that recording DMFT at a single point of time does not necessarily reflect the true oral health history, with previously carious teeth having been extracted. These factors may explain the high but not significant effect of malocclusion characteristics in this study on DMFT: additionally, caries can take a long time to manifest itself; all these could be contributing factors that weaken this association and perhaps explain the lack of increasing DMFT with age as might otherwise be expected.

The study population comprised a convenience sample from those who were attending dental clinics-the potential for bias exists with the possibility that those refugees who do not attend the dental clinics may have different disease rates or behavior. Despite these limitations, this study is the first to fill the gap in the literature by reporting on the oral health status of Syrian child refugees and their oral health needs, highlighting some of the challenges and malocclusion conditions that are experienced by this underprivileged population. These further complicate the oral health status in addition to factors such as limited facilities and accessibility to appropriate healthcare services. Maintaining meticulous oral hygiene measures is the gold standard to reduce the magnitude of the negative impact of malocclusion on oral health especially when orthodontic treatment is not available, as in the case for this population. This highlights the significance of implementing efficient targeted health promotion and preventive programs for this disadvantaged group.

\section{Conclusions}

In the current study, inferior oral health status of Syrian refugee children/adolescents aged 7-19 years with high prevalence of dental caries was confirmed. Poor oral hygiene practices dominate the oral healthcare attitudes in the examined population, partly indicating the lack of dental services. Malocclusion is associated with oral hygiene and caries experience, which may justify the provision of orthodontic treatment for those children with severe malocclusion traits. Consequently, educational, preventive and curative programs should be implemented to improve child refugee dental care, especially those at high risk with severe malocclusion traits.

\section{Abbreviations \\ DHC: Dental health component; DMFT/dmft: Mean of decayed, missing, and filled permanent teeth/ deciduous.; IOTN: Index of orthodontic treatment need; OHI-S: Simplified oral hygiene index; SD: Standard deviation; SiC: Signifi- cant caries index; WHO: World health organization.}

\section{Acknowledgements \\ Not applicable.}

\section{Authors' contributions}

NS conceived the ideas, data collection and led the writing; RO did parts of data collection and writing; MA analyzed the data and helped in article writing and primary review; AA did parts of writing and primary review and JS did writing and critical review of the manuscript. All authors read and approved the final manuscript.

\section{Funding}

This research received no specific grant from any funding agency in the public, commercial, or not-for-profit sectors.

\section{Availability of data and materials}

All collected data from patients analyzed during this study are included in this published article. The datasets used and analyzed during the current study are available from the corresponding author on reasonable request.

\section{Declarations}

Ethics approval and consent to participate

This study was reviewed and approved by the Research Ethics Committee in of the Faculty of Dentistry of the University of Jordan (Reference: 75/2020/71) and in full accordance with the world medical Declaration of Helsinki. Written informed consent was obtained from parents (or guardians) of participants.

\section{Consent for publication}

Not applicable.

\section{Competing interests}

The authors declare that they have no competing interests.

\section{Author details}

${ }^{1}$ Prosthodontic Department, School of Dentistry, The University of Jordan, Amman 11942, Jordan. ${ }^{2}$ Department of Paediatric Dentistry, Orthodontics, and Preventive Dentistry, School of Dentistry, The University of Jordan, Amman, Jordan. ${ }^{3}$ Department of Conservative Dentistry, School of Dentistry, The University of Jordan, Amman, Jordan. ${ }^{4}$ Division of Dentistry, School of Medical Sciences, University of Manchester, Oxford Road, Manchester M13 9PL, UK.

Received: 22 June 2021 Accepted: 26 November 2021

Published online: 07 December 2021 


\section{References}

1. Ngom PI, Diagne F, Aidara-Tamba AW, Sene A. Relationship between orthodontic anomalies and masticatory function in adults. Am J Orthod Dentofacial Orthop. 2007;131(2):216-22.

2. Ngom PI, Diagne F, Benoist HM, Thiam F. Intraarch and interarch relationships of the anterior teeth and periodontal conditions. Angle Orthod. 2006;76(2):236-42.

3. Hanna A, Chaaya M, Moukarzel C, El Asmar K, Jaffa M, Ghafari JG. Malocclusion in elementary school children in beirut: severity and related social/ behavioral factors. Int J Dent. 2015;351231:1-10.

4. Nobile CG, Pavia M, Fortunato L, Angelillo IF. Prevalence and factors related to malocclusion and orthodontic treatment need in children and adolescents in Italy. Eur J Public Health. 2007;17(6):637-41.

5. Abu Alhaija ES, Al-Khateeb SN, Al-Nimri KS. Prevalence of malocclusion in 13-15 year-old North Jordanian school children. Community Dent Health. 2005;22(4):266-71.

6. Ciuffolo F, Manzoli L, D'Attilio M, Tecco S, Muratore F, Festa F, Romano F. Prevalence and distribution by gender of occlusal characteristics in a sample of Italian secondary school students: a cross-sectional study. Eur J Orthod. 2005:27(6):601-6.

7. Hamdan AM. The relationship between patient, parent and clinician perceived need and normative orthodontic treatment need. Eur J Orthod. 2004;26(3):265-71.

8. Oh TJ, Eber R, Wang HL. Periodontal diseases in the child and adolescent. J Clin Periodontol. 2002;29(5):400-10.

9. Bourgeois D, Llodra J. Global burden of dental condition among children in nine countries participating in an international oral health promotion programme, 2012-2013. Int Dent J. 2014;64(Suppl 2):27-34

10. Davies TM, Shaw WC, Worthington HV, Addy M, Dummer P, Kingdon A. The effect of orthodontic treatment on plaque and gingivitis. Am J Orthod Dentofacial Orthop. 1991:99(2):155-61.

11. Geiger A. Malocclusion as an etiologic factor in periodontal disease: a retrospective essay. Am J Orthod Dentofacial Orthop. 2001;120(2):112-5.

12. Helm S, Petersen PE. Causal relation between malocclusion and caries. Acta Odontol Scand. 1989;47(4):217-21.

13. Aamodt K, Reyna-Blanco O, Sosa R, Hsieh R, De la Garza RM, Garcia Martinez M, Orellana MF. Prevalence of caries and malocclusion in an indigenous population in Chiapas. Mexico Int Dent J. 2015;65(5):249-55.

14. Arora G, Bhateja S. Prevalence of dental caries, periodontitis, and oral hygiene status among 12-year-old schoolchildren having normal occlusion and malocclusion in Mathura city: a comparative epidemiological study. Indian J Dent Res. 2015:26(1):48-52

15. Stahl F, Grabowski R. Malocclusion and caries prevalence: is there a connection in the primary and mixed dentitions? Clin Oral Investig. 2004;8(2):86-90.

16. Eismann D, Prusas R. Periodontal findings before and after orthodontic therapy in cases of incisor cross-bite. Eur J Orthod. 1990;12(3):281-3.

17. Hashim HA, Al-Jasser NM. Periodontal findings in cases of posterior crossbite. J Clin Pediatr Dent. 1996;20(4):317-20.

18. Ashley FP, Usiskin LA, Wilson RF, Wagaiyu E. The relationship between irregularity of the incisor teeth, plaque, and gingivitis: a study in a group of schoolchildren aged 11-14 years. Eur J Orthod. 1998;20(1):65-72.

19. Baskaradoss JK, Geevarghese A, Roger C, Thaliath A. Prevalence of malocclusion and its relationship with caries among school children aged 11-15 years in southern India. Korean J Orthod. 2013;43(1):35-41.

20. Vellappally S, Gardens SJ, Al Kheraif AA, Krishna M, Babu S, Hashem M, Jacob V, Anil S. The prevalence of malocclusion and its association with dental caries among 12-18-year-old disabled adolescents. BMC Oral Health. 2014;14:123.

21. UNHCR. The United Nations High Commissioners for refugees [online] (2020). Syria Regional Refugee Response. Available from: https://data2. unhcr.org/en/situations/syria/location/36.

22. Barazanchi A, Nabhani A, Chen A, Smith M, Broadbent J. Oral health care needs among former refugees of the war in Syria. N Z Dent J. 2018:114:117-23.

23. Salim NA, Maayta W, ElSa'aideh BB. The oral health of refugees: Issues and challenges arising from a case series analysis. Community Dent Oral Epidemiol. 2020;48(3):195-200.

24. Salim NA, Maayta W, Hassona Y, Hammad M. Oral health status and risk determinants in adult Syrian refugees in Jordan: a cross sectional study. Community Dent Health. 2020;37:1-6.
25. Salim NA, Shaini FJ, Sartawi S, Al-Shboul B. Oral health status and dental treatment needs in Syrian refugee children in Zaatari camp. J Refug Stud. 2021. https://doi.org/10.1093/jrs/feaa133.

26. Josefsson E. Immigrant background and orthodontic treatment need. Quantitative and qualitative studies in Swedish adolescents. Swed Dent J Suppl. 2010;207:1-92.

27. Josefsson E, Bjerklin K, Lindsten R. Factors determining perceived orthodontic treatment need in adolescents of Swedish and immigrant background. Eur J Orthod. 2009:31(1):95-102.

28. WHO (World Health Organization), Oral Health Surveys: Basic Methods, World HealthOrganization, Geneva, Switzerland, 4th edition, 1997. WHO Collaborating Centre. Faculty of Odontology, University of Malmö, Sweden. PDF Vers. 1.0; 2001-03-6.

29. Suresh K, Chandrashekara S. Sample size estimation and power analysis for clinical research studies. J Hum Reprod Sci. 2012;5(1):7-13.

30. WHO Collaborating Centre. Faculty of Odontology, University of Malmö, Sweden. PDF Vers. 1.0; 2001-03-6 http://www.whocollab.od.mah.se/expl/ siccalculation.xls

31. Rodrigues CR, Ando T, Guimaraes LO. Simplified oral hygiene index for ages 4 to 6 and 7 to 10 (deciduous and mixed dentition). Rev Odontol Univ Sao Paulo. 1990;4(1):20-4.

32. Salim NA, Al-Abdullah MM, AlHamdan AS, Satterthwaite JD. Prevalence of malocclusion and assessment of orthodontic treatment needs among Syrian refugee children and adolescents: a cross-sectional study. BMC Oral Health. 2021;21(1):305.

33. Keboa MT, Hiles N, Macdonald ME. The oral health of refugees and asylum seekers: a scoping review. Global Health. 2016;12(1):59.

34. Quach A, Laemmle-Ruff IL, Polizzi T, Paxton GA. Gaps in smiles and services: a cross-sectional study of dental caries in refugee-background children. BMC Oral Health. 2015;15:1-10.

35. Hamdan M, Hamdan A, Karien GH, Abu-Ghazaleh S, Sonbol H, Al-Abdallah M, Rajab L. Prevalence of preschool caries among 6-year-old school children from different socioeconomic backgrounds in Amman. Jordan Jordan Med J. 2013:47(3):227-40.

36. Salim NA, ElSa'aideh BB, Maayta W, Hassona Y. Dental services provided to Syrian refugee children in Jordan, a retrospective study. Spec Care Dentist. 2020;40(3):1-7.

37. Smadi L, Azab R, Khlaifat F, Rodan R, Abdalmohdi A, Maata R, Bny Mfarej E. Prevalence and severity of dental caries in school students aged 6-12 years in Mafraq governorate: Northeast of Jordan. J Oral Health Oral Epidemiol. 2017;6(1):40-7.

38. Salim NA, Tiwari T. Migrant and refugee Oral Health. Community Dent Health. 2021;38(1):3-4

39. Salim NA, Meyad SH, Sawair FA, Satterthwaite JD, Sartawi S. Satisfaction with healthcare services among refugees in Zaatari camp in Jordan. BMC Health Serv Res. 2021;21(1):507.

40. Mamai-Homata E, Koletsi-Kounari H, Margaritis V. Gender differences in oral health status and behavior of Greek dental students: a meta-analysis of 1981, 2000, and 2010 data. J Int Soc Prev Community Dent. 2016:6(1):60-8.

41. Helm S, Petersen PE. Causal relation between malocclusion and periodontal health. Acta Odontol Scand. 1989:47(4):223-8.

42. Abu Alhaija ES, Al-Wahadni AM. Relationship between tooth irregularity and periodontal disease in children with regular dental visits. J Clin Pediatr Dent. 2006;30(4):296-8

43. Caplin JL, Evans CA, Begole EA. The Relationship between Caries and Malocclusion in Chinese Migrant Workers' Children in Shanghai. Chin J Dent Res. 2015;18(2):103-10.

44. Selwitz RH, Ismail Al, Pitts NB. Dental caries. Lancet. 2007;369(9555):51-9.

45. Staufer $\mathrm{K}$, Landmesser $\mathrm{H}$. Effects of crowding in the lower anterior segmenta risk evaluation depending upon the degree of crowding. J Orofac Orthop. 2004;65(1):13-25.

46. Glans R, Larsson E, Ogaard B. Longitudinal changes in gingival condition in crowded and noncrowded dentitions subjected to fixed orthodontic treatment. Am J Orthod Dentofacial Orthop. 2003;124(6):679-82.

\section{Publisher's Note}

Springer Nature remains neutral with regard to jurisdictional claims in published maps and institutional affiliations. 